\title{
Imagen parcheada por permanencia de la capa predescemética tras queratoplastia endotelial de membrana de Descemet
}

\section{Patched image due to pre-Descemet remains after Descemet membrane endothelial keratoplasty}

\author{
Irene Blanco-Domínguez*, Josep Torras-Sanvicens y Jorge Peraza-Nieves
}

Instituto Clínic de Oftalmología (ICOF), Hospital Clínic, Barcelona, España

Mujer pseudofáquica de 59 años a la que se practica una queratoplastia endotelial de membrana de Descemet, sin incidencias, por una distrofia de Fuchs descompensada. Al mes, la agudeza visual es de 20/20 y en la biomicroscopía se observa una córnea central transparente con una imagen parcheada sugestiva de la presencia de la capa predescemética receptora en la interfase ${ }^{1,2}$ (Fig. 1A). Se realiza una tomografía de coherencia óptica de segmento anterior (Topcon DRI-OCT Triton Sweptsource()) que refuerza la sospecha de eliminación parcial de la capa predescemética durante la descematorrexis, mostrando una imagen de doble capa (superposición del injerto sobre la capa predescemética del receptor) (Fig. 1B).

\section{Conflicto de intereses}

Los autores declaran no tener ningún conflicto de intereses.

\section{Responsabilidades éticas}

Protección de personas y animales. Los autores declaran que para esta investigación no se han realizado experimentos en seres humanos ni en animales.

Confidencialidad de los datos. Los autores declaran que han seguido los protocolos de su centro de trabajo sobre la publicación de datos de pacientes.

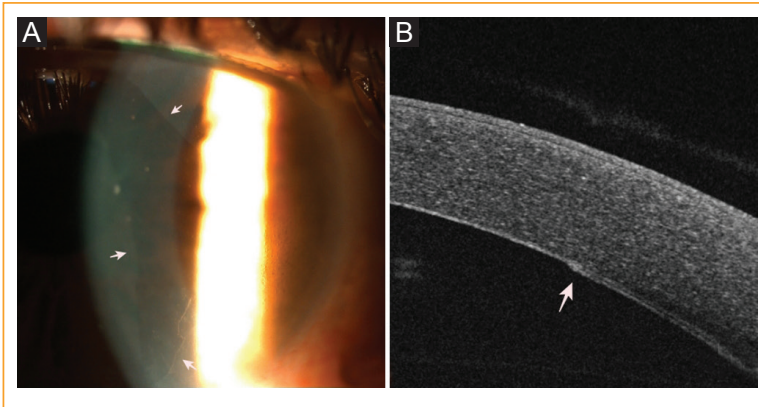

Figura 1. A: imagen de lámpara de hendidura; las flechas blancas muestran el área del injerto sin la capa de Dua o capa predescemética. B: imagen OCT; la flecha blanca muestra la doble capa (injerto DMEK + capa de Dua predescemética del huésped).

Derecho a la privacidad y consentimiento informado. Los autores han obtenido el consentimiento informado de los pacientes y/o sujetos referidos en el artículo. Este documento obra en poder del autor de correspondencia.

\section{Bibliografía}

1. Agarwal A, Dua HS, Narang P, Kumar DA, Agarwal A, Jacob S, et al Pre-Descemet's endothelial keratoplasty (PDEK). Br J Ophthalmol. 2014;98:1181-5.

2. Dua HS, Faraj LA, Said DG, Gray T, Lowe J. A novel pre-Descemet's layer (Dua's layer). Ophthalmology. 2013;120:1778-85. 